\title{
Comparison of rectal and tympanic membrane temperature in healthy exercising dogs.
}

\author{
Published version: ISSN 1755-2540 print, ISSN 1755-2559 online, \\ DOI 10.3920/CEP160034
}

\section{Authors:}

\section{E. J. Hall MA VetMB AFHEA MRSB MRCVS}

Nottingham Trent University - Brackenhurst Campus,

School of Animal, Rural and Environmental Sciences

Southwell, Nottinghamshire,

NG25 0QF, UK

E-mail for correspondence: emily.hall@ ntu.ac.uk

\author{
A. J. Carter BSc (Hons) MSc PhD PGCEP FHEA MRSB \\ Nottingham Trent University - Brackenhurst Campus, \\ School of Animal, Rural and Environmental Sciences \\ Southwell, Nottinghamshire, \\ NG25 0QF, UK
}

\section{Running header:}

Comparison of rectal and tympanic membrane temperature in exercising dogs.

\begin{abstract}
The ability to monitor body temperature in athletes at risk of hyperthermia is essential in all species. Currently, the only commonly accepted temperature monitoring site in dogs is the rectum. This is impractical in field situations as it takes time, requires additional handlers to restrain the dog and is not tolerated by all animals. Tympanic membrane temperature (TMT) monitoring may provide a rapid measure of body temperature to facilitate identification of heat stress and heat stroke in canine athletes. In human studies, TMT diverges from rectal temperature (RT) as body temperature increases
\end{abstract}


during exercise induced hyperthermia so is not recommended for monitoring human athletes. If the same divergence occurs in dogs, TMT may not be suitable for use when monitoring the temperature of canine athletes.

The aim of the study was to determine if TMT diverged from RT following exercise in healthy dogs.

24 healthy dogs were recruited to the study. Body temperature was measured using a veterinary auricular infrared thermometer (VetTemp) to record tympanic membrane temperature and an electric predictive rectal thermometer. Temperatures were recorded pre and post exercise in a non-clinical setting, familiar to the dogs.

The mixed model approach showed that exercise had no effect on the difference between RT and TMT $\left(\mathrm{F}_{(1,201)}=0.026, \mathrm{P}=0.872\right)$. The overall mean difference of RT minus TMT was $0.39^{\circ} \mathrm{C}(\mathrm{n}=$ 116). $68.4 \%$ of readings fell within the accepted $0.5^{\circ} \mathrm{C}$ difference in temperature recording method.

In line with previously reported TMT to RT comparison studies in dogs, this study found that TMT measured consistently lower than RT. Using a correction factor of $0.4^{\circ} \mathrm{C}$ minimised the difference. The hypothesis that dogs would show greater differences between TMT and RT following exercise was not supported, suggesting that TMT could be used to monitor body temperature in exercising dogs where RT is not possible.

Keywords: hyperthermia, canine athlete, aural thermometer, temperature monitoring

\section{Introduction}

Exertional heat stroke occurs when core temperature exceeds the body's thermoregulatory mechanism, typically after strenuous exercise, when athletes are not appropriately acclimatised to the ambient conditions, or when exercising in high ambient temperatures (Reniker and Mann, 2002). As the popularity of canine sports continues to increase (The Kennel Club, 2016) there is an increased risk of exertional heat stroke occurring (Hall and Carter, 2016). The ability to measure canine athlete temperatures during training and racing events is essential for identifying those at risk of heat injury, as rapid treatment has been shown to reduce mortality (Bruchim et al., 2006).

The ability to estimate body temperature is essential for animal welfare, as core temperature measurements from the trachea, oesophagus or a central vascular space require the use of invasive and potentially painful techniques which are impractical for most field or clinical settings (Miller, 2009). There are a number of non-invasive body temperature monitoring devices, however the literature to support their use is lacking.

Rectal temperature (RT) is the most widely used method of estimating core temperature in veterinary medicine (Greer et al., 2007; Southward et al., 2006), however this method is not tolerated in all dogs (Lamb and McBrearty, 2013) and can prove impractical in non-clinical situations. Where rectal temperature is tolerated, assistance is often required in order to restrain the patient for temperature measurement. Lamb and McBrearty (2011) reported that $45.5 \%$ of conscious canine patients required additional restraint. For these reasons there has been continued interest in alternative methods of estimating core temperature, such as infrared auricular thermometers, axillary temperature recording and the use of infrared thermography (Lamb and McBrearty, 2013; Yanmaz et al., 2015). Infrared auricular thermometers measure the tympanic membrane temperature (TMT) and provide an attractive alternative to RT measurement, both in terms of speed (Greer et al., 2007) and patient tolerance. Lamb and McBrearty (2011) found that conscious canine patients were less likely to require additional restraint for TMT measurement than RT measurement. 
However, auricular thermometers have been found to vary in accuracy at predicting RT with mean RT minus TMT differences ranging from $-0.015^{\circ} \mathrm{C}$ to $1.27^{\circ} \mathrm{C}$ (Huang and Shih, 1998; Huang and Huang, 1999; Rexroat et al., 1999; Southward et al., 2006; Piccione et al., 2011; Sousa et al., 2011 and 2013; Konietschke et al., 2014; Yanmaz et al., 2015). This variation may be due to the use of nonveterinary specific auricular thermometers. The veterinary specific devices appear to be more reliable with mean differences ranging from $-0.015^{\circ} \mathrm{C}$ to $0.77^{\circ} \mathrm{C}$ (Rexroat et al., 1999; Gonzalez et al., 2002; Wiedemann et al., 2006; Greer et al., 2007; Piccione et al., 2011; Lamb et al., 2013; Gomart et al., 2014; Smith et al., 2015). The majority of these studies report that TMT measures consistently lower than rectal temperature. Improved accuracy of the veterinary specific thermometer has been reported in hypothermic patients when compared to hyperthermic patients in a clinical setting (Greer et al., 2007). Southward el al. (2006) hypothesised that the device would be less accurate in hyperthermic patients, based on results from the human literature. The findings of Greer et al. (2007) were in support of this theory, however, they investigated anaesthetised laboratory animals with endotoxin induced hyperthermia. To date, the effects of physiological, exercise induced hyperthermia on device accuracy have not been investigated in canine athletes.

Within the human medicine literature, a review of TMT versus RT in exercising, hyperthermic athletes, found that TMT increasingly diverges from RT as athlete temperature increases (Huggins $e t$ al., 2012). Due to the potential risk of under reporting hyperthermia, it has been suggested that TMT is not a suitable method of monitoring body temperature in human athletes. If this divergence is also present in canine athletes, the same limitations will apply to the tympanic membrane (TM) thermometer, namely underreporting hyperthermia.

The need to monitor canine temperature is not restricted to veterinary settings. Where activities take place in warmer climates, there is an increased risk of both environmental and exertional heat stroke (Johnson et al., 2006). Non-invasive methods of monitoring temperature should ideally be available to ensure rapid identification of animals suffering from heat stress and heat stroke, as morbidity and mortality both reduce if the animal is presented quickly for veterinary care (Bruchim et al., 2006). Increasingly pet owners are becoming aware of the technology available for monitoring their pets' vital signs, including animal specific health monitoring devices such as the PetPace collar, the Voyce Health Monitor collar, and animal specific TM thermometers such as the Pet-Temp Instant Ear Thermometers. As participation in canine sporting activities increases, owner interest in canine athletic performance and health monitoring is also likely to increase. Within canine sport, owners are beginning to be encouraged to monitor temperature as a sign of performance (Canine Health Foundation, 2015). Internet forums also show that owners are monitoring their dog's temperature using these devices when deciding whether to seek veterinary advice for a sick animal. It is therefore essential that pet owners and professionals are made aware of any potential limitations of this method of temperature measurement. If aural thermometers are to be used by pet owners in a non-clinical setting, a normal temperature range for TMT is necessary in order to prevent hyperthermia going undetected.

Gomart et al. (2014) published a table of correction factors for use with the Pet-Temp, to predict RT from TMT measurement, but do not comment on statistical impact of applying these factors.

However, their study was limited to hospitalised, clinical canine patients and concluded that further investigation was needed to evaluate these techniques in hyperthermic dogs. To date, no other TMT to RT comparison study has used healthy exercising dogs, away from a clinical veterinary setting. As body temperature can increase with anxiety (Levy et al, 2015), this study was conducted in a nonclinical setting to ensure dogs were not stressed by an unfamiliar environment.

The aim of the study was to determine if TMT diverged from RT following routine daily exercise, in a group of healthy dogs in a non-veterinary environment. The effect of a correction factor on TMT was also investigated, to determine if this improved detection of hyperthermia when compared to RT. 
The impact of ambient conditions on the difference between the two thermometers was also monitored.

\section{Material and Methods}

The study was approved by the Nottingham Trent University's School of Animal, Rural and Environmental Science's ethics approval group.

\section{Animals}

Dogs were recruited from a population of university staff owned pets and members of a local canine sporting club. Owners were required to confirm that their dogs were fit and healthy, not undergoing veterinary treatment and showing no clinical evidence of otitis externa. Sample size was determined by pre study power analysis, at least 22 dogs were needed to achieve a study power of $80 \%$, with an error $=0.05$, to detect a $0.6^{\circ} \mathrm{C}\left(\mathrm{SD} 1{ }^{\circ} \mathrm{C}\right)$ difference between the two methods. This was based on the mean TMT of the sample population reported by Gomart et al. (2014). Twenty-four dogs (15 males, 9 females) were recruited, representing eight breed types: cocker spaniel $(n=4)$, Labrador retrievers $(n=4)$, lurchers $(n=3)$, welsh springer spaniels $(n=2)$, pugs $(n=2)$, pointer $(n=1)$, springer spaniel $(n=1)$ and cross breeds $(n=3)$. Ages ranged from 6 months to 15 years. All temperature recordings were taken during periods of the dogs' routine exercise, taking place in the East Midlands, UK, throughout a twelve-month period. The purpose of the period of exercise was to elevate body temperature in a non-clinical, physiological manner. In order to limit the impact of the study on the dog's normal routine, the duration, type and intensity of exercise completed was not standardised. The types of exercise included brisk walking on lead, free running off lead and off lead play but was of at least 20 minutes duration.

\section{Temperature measurements}

TMT was recorded using one new Vet-Temp VT-150 Instant Ear Thermometer (Advanced Monitors Corporation, California, USA), covered by a single use Vet-Temp DPC-500 probe cover (Advanced Monitors Corporation, California, USA). The Vet-Temp thermometer measures temperatures between $32.2-43.3^{\circ} \mathrm{C}$, with an accuracy of $\pm 0.2^{\circ} \mathrm{C}$. The thermometer was used as per the manufacturer's instructions (see Fig 1), with no lubrication and a reading being obtained following the audible alarm. If a reading reported an error code, the probe cover was changed, and the process repeated.

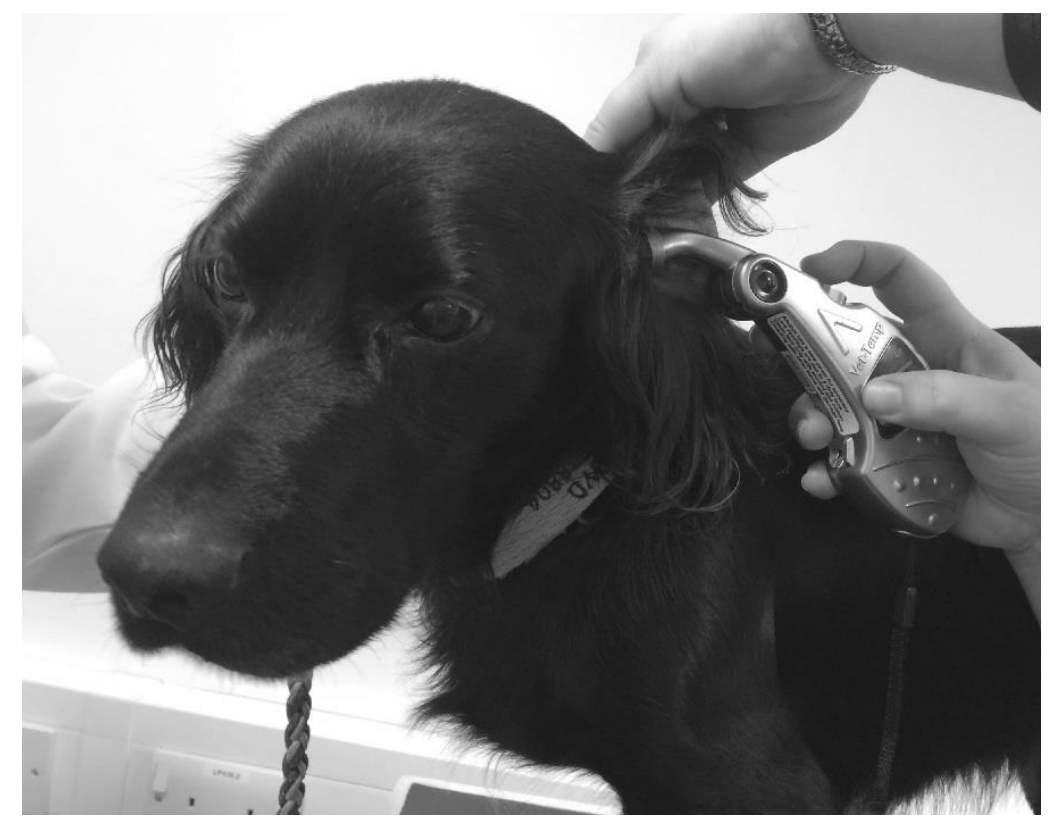


Figure 1. A Vet-Temp auricular thermometer being used: the dog's ear is pulled out and down, with the probe angled towards the opposite jaw (a probe cover is in place but not visible in this picture).

Rectal temperature was recorded using a V966F Vicks Comfortflex Digital Thermometer (KAZ Incorporated, New York, USA), which alarms once a stable peak temperature is reached. The Comfortflex Digital Thermometer measures temperatures between $32-42.9{ }^{\circ} \mathrm{C}$ with an accuracy of $\pm 0.2^{\circ} \mathrm{C}$ at room temperature. Prior to the study, the thermometer was tested in water baths of $35^{\circ} \mathrm{C}$ and $40^{\circ} \mathrm{C}$ and found to be within $0.1^{\circ} \mathrm{C}$ of the reference mercury thermometer. The thermometer was lubricated using K-Y jelly (Johnson \& Johnson, France), inserted at least $2 \mathrm{~cm}$ into the rectum and held against the rectal wall until the alarm sounded.

All readings were collected by one author to remove any operator bias, and both thermometers were familiar to the author through routine use in clinical practice. All dogs were lightly restrained by an assistant for both temperature recordings. Individuals involved in taking temperature and restraint of the dogs were familiar to the dogs. In all cases, TMT was recorded first, to limit any influence stress response to the RT recording could have on the results. Left or right ears were selected at random depending on the positioning of the patient following restraint, to reflect the likely situation in a clinical practice or home environment.

Both TMT and RT recordings were taken at rest, and immediately following a period of exercise to elevate core temperature. Where geographical location allowed, repeated measures were taken (17/24 dogs) in order to assess any consistency of variation in individual animals. The ambient temperature, relative humidity and wind speed were recorded for every period of exercise. Over the course of the study, mean value for ambient temperature was $12.5^{\circ} \mathrm{C}$ (range $4.9-20.5^{\circ} \mathrm{C}$ ), windspeed was $2.44 \mathrm{~m} / \mathrm{s}$ (range $0.36-6.64 \mathrm{~m} / \mathrm{s}$ ) and relative humidity was $68.4 \%$ (range $42.5-92.9 \%$ ). Measurements were taken using a HI 9564 Thermo Hygrometer (Hanna Instruments Lid, Bedfordshire, UK), and RD 5069650 Anemometer (R.S. Components Ltd., Northamptonshire, UK). In order to evaluate the overall impact of these environmental conditions, the results were used to calculate Universal Thermal Comfort Index (UTCI) values (Jendritzy et al., 2012). UTCI was calculated from ambient temperature $\left({ }^{\circ} \mathrm{C}\right)$, relative humidity $(\%)$ and wind speed $(\mathrm{m} / \mathrm{s})$ using the UTCI calculator (http://www.utci.org/) and varied from $-2.6^{\circ} \mathrm{C}$ to $15.6^{\circ} \mathrm{C}$.

\section{Statistical analysis}

Statistics were calculated using SPSS 23.0 (SPSS Inc., Chicago, USA). Mixed linear model was used to compare RT and TMT. The measurement site (ear (TMT) and rectum (RT)) and exercise (pre and post exercise) were included as fixed effects. Dog was included as a random effect. Comparisons were made between temperature pre and post exercise, RT and TMT and the interaction between site and exercise.

Mixed linear model was also used to compare the difference in temperature (RT minus TMT) pre and post exercise. Exercise was included as a fixed effect and dog as a random effect. Spearman's rho test was used to assess correlation between ambient conditions (UTCI) and RT minus TMT, as UTCI was not normally distributed.

As the number of repeat measures per individual was not constant (due to availability and exercise regime of the animals) and the repeated measures were taken on different days and under different environmental conditions (resulting in variable resting body temperatures), the use of a Bland-Altman plot was deemed inappropriate (Hartnack, 2014). A scatter plot was instead used to provide a visual assessment of the difference between the two sites. Significance was indicated at $\mathrm{P}<0.05$ for all tests. In line with previous studies an acceptable limit of difference between the two temperature recording sites was set at $\pm 0.5^{\circ} \mathrm{C}$. 


\section{Results}

A total of 116 paired temperature measurements were recorded, ranging from 1 to 8 paired measurements per $\operatorname{dog}($ median $=6$, mean $=4.6)$. Pre exercise $\mathrm{RT}$ readings ranged from $37.4^{\circ} \mathrm{C}$ to $39.1^{\circ} \mathrm{C}\left(\right.$ mean $=38.3^{\circ} \mathrm{C}$ ) and TMT ranged from $36.7^{\circ} \mathrm{C}$ to $38.8^{\circ} \mathrm{C}\left(\right.$ mean $\left.=37.9^{\circ} \mathrm{C}\right)$. Post exercise RT readings ranged from $38.3^{\circ} \mathrm{C}$ to $40.0^{\circ} \mathrm{C}$ (mean $=39.0^{\circ} \mathrm{C}$ ) and $\mathrm{TMT}$ ranged from $37.4^{\circ} \mathrm{C}$ to $39.7^{\circ} \mathrm{C}$ $\left(\right.$ mean $=38.6^{\circ} \mathrm{C}$ ). The range of RT increase recorded following exercise was $0.1-1.4^{\circ} \mathrm{C}$ (mean $=0.7$ ${ }^{\circ} \mathrm{C}, \mathrm{n}=58$ ). TMT under reported body temperature when compared to RT in 95 of the pair measurements $(82 \%), 80$ pairs of readings $(68.4 \%)$ fell within the accepted $0.5^{\circ} \mathrm{C}$ difference in temperature recording method (Fig 2).

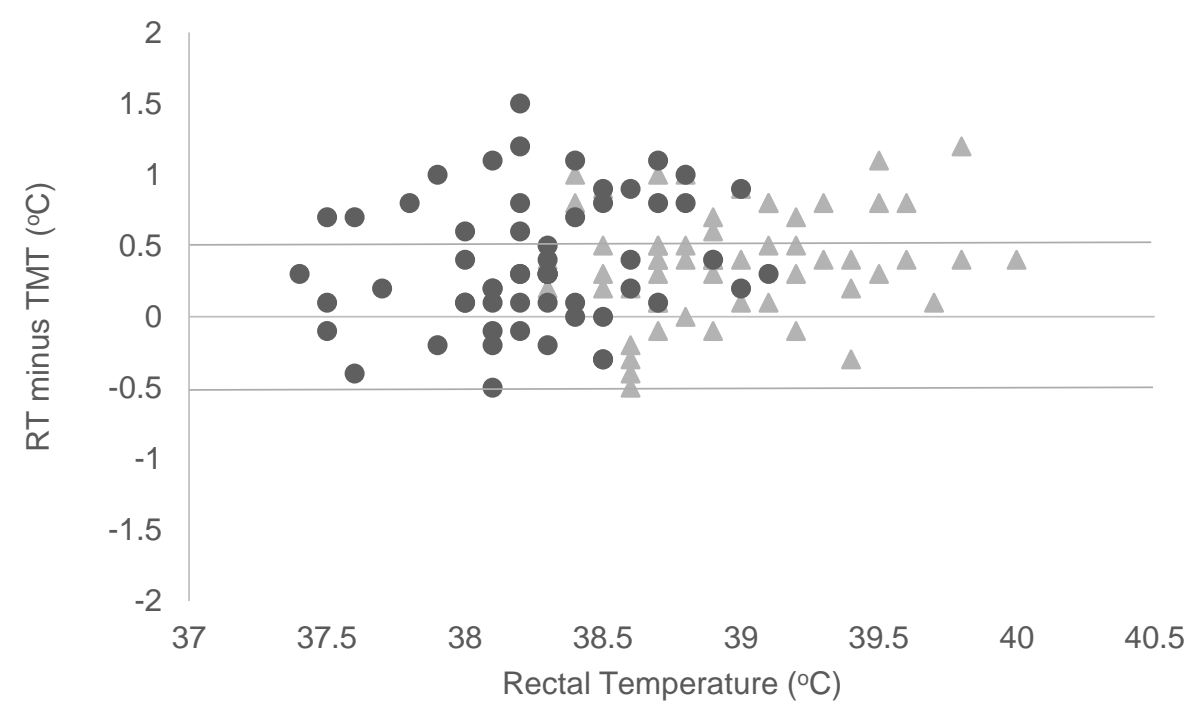

Figure 2. Rectal temperature (RT) plotted against the rectal temperature minus tympanic membrane temperature (RT minus TMT). Circles represent readings pre exercise, triangles represent readings post exercise. The solid lines represent the clinically acceptable limits of agreement between two temperature recording devices $\left( \pm 0.5^{\circ} \mathrm{C}\right)$.

The mixed model approach was used as RT minus TMT was normally distributed, this showed a significant effect of exercise $\left(\mathrm{F}_{(1,203)}=173.1, \mathrm{p}<0.0001\right)$ and measurement site $\left(\mathrm{F}_{(1,201)}=52.2\right.$, $\mathrm{p}<0.0001)$ on temperature. There was no significant interaction between exercise and measurement site $\left(\mathrm{F}_{(1,201)}=0.026, \mathrm{P}=0.872\right)$.

For all data, RT minus TMT ranged from $-0.5^{\circ} \mathrm{C}$ to $1.5^{\circ} \mathrm{C}$ (mean $\left.=0.39^{\circ} \mathrm{C}, \mathrm{n}=116\right)$. Pre exercise RT minus TMT ranged from $-0.5^{\circ} \mathrm{C}$ to $1.5^{\circ} \mathrm{C}\left(\right.$ mean $\left.=0.38^{\circ} \mathrm{C}, \mathrm{n}=58\right)$. Post exercise RT minus TMT ranged from $-0.5^{\circ} \mathrm{C}$ to $1.2^{\circ} \mathrm{C}$ (mean $=0.39, \mathrm{n}=58$ ). Table 1 shows the descriptive statistics for the two temperature measurement sites pre and post exercise. Descriptive statistics for RT minus TMT following correction of TMT by the addition of $0.4^{\circ} \mathrm{C}$ are also shown in table 1 . The overall mean difference for RT minus corrected TMT $+0.4^{\circ} \mathrm{C}$ was $-0.01^{\circ} \mathrm{C}(\mathrm{n}=116)$. 
Table 1. Descriptive statistics for (1) temperature measurement $\left({ }^{\circ} \mathrm{C}\right)$ at different sites, rectal temperature (RT) and tympanic membrane temperature (TMT) pre and post exercise, (2) the difference between RT and TMT pre and post exercise, (3) the difference between RT minus corrected TMT $+0.4^{\circ} \mathrm{C}$ pre and post exercise in healthy exercising dogs (24 dogs, 116 paired temperature measurements).

\begin{tabular}{|l|l|l|l|l|l|l|}
\hline \multirow{2}{*}{$\begin{array}{l}\text { Time of } \\
\text { reading }\end{array}$} & $\begin{array}{l}\text { Temperature } \\
\text { recorded }\left({ }^{\circ} \mathrm{C}\right)\end{array}$ & Mean & Median & $\begin{array}{l}\text { Standard } \\
\text { deviation }\end{array}$ & Minimum & Maximum \\
\hline \multirow{3}{*}{$\begin{array}{l}\text { Pre } \\
\text { exercise }\end{array}$} & RT & 38.3 & 38.3 & 0.39 & 37.4 & 39.1 \\
\cline { 2 - 7 } & TMT & 37.9 & 37.9 & 0.53 & 36.7 & 38.8 \\
\cline { 2 - 7 } & RT minus TMT & 0.38 & 0.3 & 0.45 & -0.4 & 1.5 \\
\cline { 2 - 7 } & $\begin{array}{l}\text { RT minus } \\
\text { TMT }+0.4^{\circ} \mathrm{C}\end{array}$ & -0.02 & -0.1 & 0.45 & -0.8 & 1.1 \\
\hline \multirow{2}{*}{$\begin{array}{l}\text { ext } \\
\text { exercise }\end{array}$} & RT & 39.0 & 38.9 & 0.41 & 38.3 & 40 \\
\cline { 2 - 7 } & TMT & 38.6 & 38.6 & 0.50 & 37.4 & 39.7 \\
\cline { 2 - 7 } & RT minus TMT & 0.39 & 0.4 & 0.38 & -0.5 & 1.2 \\
\cline { 2 - 5 } $\begin{array}{l}\text { RTinus } \\
\text { TMT }+0.4^{\circ} \mathrm{C}\end{array}$ & -0.01 & 0 & 0.38 & -0.9 & 0.8 \\
\hline
\end{tabular}

Figure 3 shows the RT minus TMT for each individual dog, for each repeated sample pair, and demonstrates the variability within each individual. The mean RT minus TMT for each dog ranged from $0.14^{\circ} \mathrm{C}$ to $0.87^{\circ} \mathrm{C}$, and there was no consistent difference in RT minus TMT for any animal.

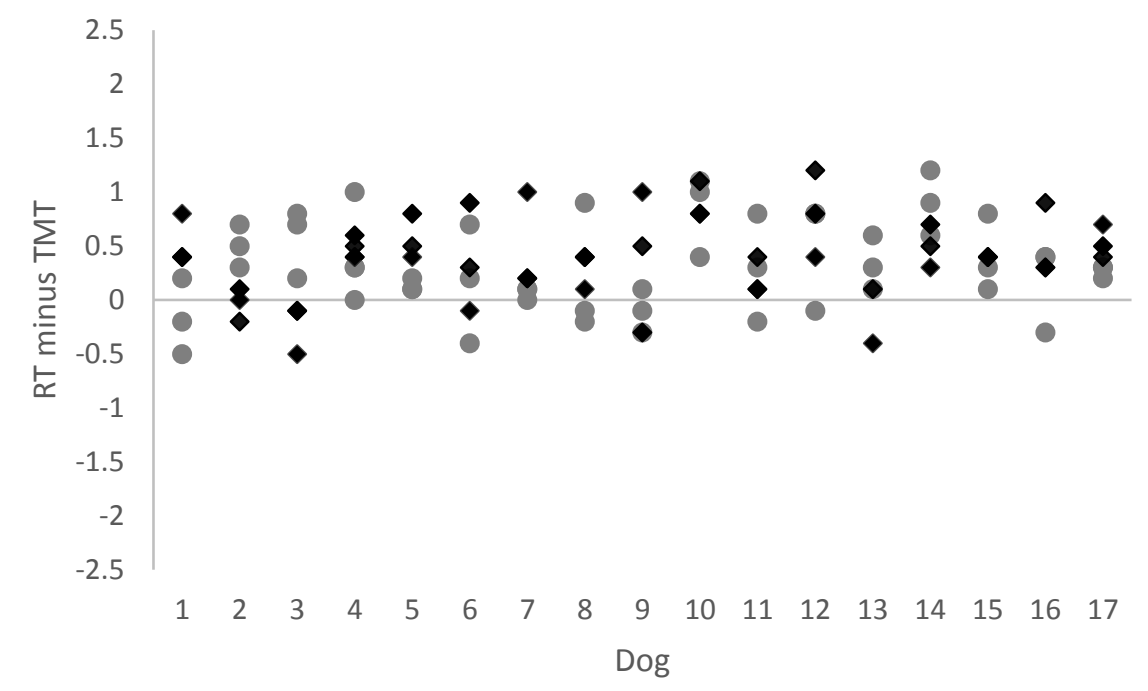

Figure 3. Rectal temperature minus tympanic membrane temperature (RT minus TMT) values for each individual dog. Circles represent readings pre exercise, triangles represent readings post exercise.

\section{Use of a correction factor}

The results of the present study (overall mean RT minus TMT $=0.39^{\circ} \mathrm{C}$ ) would support using a correction factor of $0.4^{\circ} \mathrm{C}$ for all dogs. Application of the correction factor TMT $+0.4^{\circ} \mathrm{C}$, resulted in 
92/116 (79.3\%) readings falling within the accepted $\pm 0.5^{\circ} \mathrm{C}$ RT minus TMT difference (previously $68.4 \%$ ). Repeating analysis using a mixed model approach on the TMT $+0.4^{\circ} \mathrm{C}$ showed there was then no effect of measurement site (rectal versus ear) on temperature $\left(\mathrm{F}_{(1,201)}=0.067, \mathrm{P}=0.797\right)$.

\section{Identification of hyperthermia}

Post exercise, hyperthermia was detected using RT on 14/58 (24\%) occasions, hyperthermia was defined as a rectal temperature $\geq 39.3^{\circ} \mathrm{C}$ (Miller, 2009). Hyperthermia was detected using TMT on $5 / 58(9 \%)$ occasions. The TMT thermometer identified one individual as being hyperthermic that was normothermic on RT $\left(\mathrm{RT}=39.2^{\circ} \mathrm{C}\right)$. The sensitivity and specificity of TMT in detecting hyperthermia were $33.33 \%$ and $97.73 \%$ respectively.

Application of the correction factor increased the TMT identification of the hyperthermia to 17/58 (29\%) occasions. TMT $+0.4^{\circ} \mathrm{C}$ identified seven individuals as being hyperthermic that were normothermic on RT (RT range $38.6^{\circ} \mathrm{C}$ to $39.2^{\circ} \mathrm{C}$ ). The identification of hyperthermia using $\mathrm{TMT}+0.4^{\circ} \mathrm{C}$ had a sensitivity of $71.43 \%$ and a specificity of $84.09 \%$.

\section{Impact of environmental conditions}

No significant correlation was found between UTCI and RT minus TMT $\left(\mathrm{R}_{\mathrm{s}}=0.47 . \mathrm{n}=116, \mathrm{P}=\right.$ $0.615)$.

\section{Discussion}

Human research shows that TMT diverges from RT during exercise induced hyperthermia (Huggins et al., 2012). In contrast, the present study in dogs found no significant difference in RT minus TMT between pre and post exercise. This suggests that TMT may be suitable as an alternative means of monitoring body temperature in exercising dogs.

The acceptable limit of difference between two temperature monitoring devices is generally reported as $\pm 0.5^{\circ} \mathrm{C}$ in both human and animal studies (Greer et al., 2007; Sousa et al., 2011; Lamb and McBrearty, 2013; Niven et al., 2015). Using the raw data collected in this study, $31.6 \%$ of TMT readings fell outside the accepted $0.5^{\circ} \mathrm{C}$ difference, similar to the findings reported by Lamb and McBrearty (2013). Therefore, it could be argued this method of temperature measurement is not clinically acceptable.

Rectal temperature does not represent core blood temperature. Rectal temperature readings can be influenced by the presence of faecal material, rectal inflammation and changes in blood supply to the rectum. Greer et al., (2007) demonstrated that canine pulmonary artery temperature differed to simultaneous RT recordings by more than $0.5^{\circ} \mathrm{C}$ in $5.72 \%$ of readings, and found that RT frequently recorded temperatures higher than true core temperature (189/297 readings). In human paediatric patients, rectal temperature has been shown to lag behind temporal artery temperature as cooling occurs (Greenes and Fleisher, 2004). In exercising adults TMT has been shown to peak earlier than RT, with RT continuing to increase 5-10 minutes after the cessation of exercise (Newsham et al., 2002). To the author's knowledge there are no published studies investigating this potential lag between rectal and blood temperature during post exercise cooling in dogs. Greer et al. (2007) suggested that a lag could be responsible for the differences between rectal and pulmonary artery temperature recordings in anaesthetised dogs, however this was not specifically analysed or investigated. Osinchuk et al. (2014) used ingestible telemetry devices to compare rectal to core gastrointestinal temperature in exercising dogs. They reported that core temperature increased and decreased faster than rectal temperature, suggesting that rectal temperature lags behind core temperature in strenuously exercising dogs. 
As the type and duration of exercise being undertaken by the dogs in this study was not controlled, it is possible that some dogs could have begun cooling prior to temperature measurement. This could potentially explain some of the differences seen between RT and TMT. The tympanic membrane unlike the rectal mucosa, is also in contact with the air so could potentially be influenced by ambient conditions. The temperature readings in this study were taken all year round, in all seasons and types of weather, resulting in a wide range of ambient conditions and no correlation was found between ambient conditions and RT minus TMT.

When evaluating body temperature in any animal, it is standard practice to make a comparison to the normal reference range for that species in order to categorise the patient as normothermic, hypothermic or hyperthermic. Normal reference ranges for canine rectal temperature vary amongst the literature and the data to support these ranges is not always referenced. For example, one text states a normal range of $38.3-38.7^{\circ} \mathrm{C}$ (Seymour, 2007), then states a range of $38.3-39.2^{\circ} \mathrm{C}$ (Goddard and Phillips, 2011) in the following edition, with no reference to the primary sources of information. The range of RT recorded in resting healthy dogs in this study was $37.4-39.1^{\circ} \mathrm{C}$, possibly a reflection of the low stress, familiar environment in which the temperatures were measured. In the present study, a short period of exercise increased RT by up to $1.4^{\circ} \mathrm{C}$. This is comparable to dogs undertaking a short walk to the practice, or experiencing a period of stress whilst in the waiting room, therefore temperatures recorded in a clinical setting have the potential to be elevated beyond the dog's normal resting temperature. Konietschke et al., (2014) highlighted the lack of consistent reference ranges for dogs, in particular at the lower limit, and reported a similar range of temperatures from healthy dogs, $37.2-39.2^{\circ} \mathrm{C}$, perhaps suggesting the need for a review of the standard canine rectal temperature reference range. A review of normal rectal temperatures in cats, highlighted a similar lack of consistent reference ranges, and suggested a new reference interval of $36.7-38.9^{\circ} \mathrm{C}$ following examination of healthy adult cats acclimatised to their environments (Levy et al., 2015).

Of particular importance is the upper limit for normal temperature, most commonly stated as $39.2^{\circ} \mathrm{C}$ (Miller, 2009). Heat stroke, is a potentially fatal condition in all species, and in dogs can occur once core body temperature exceeds $41^{\circ} \mathrm{C}$ (Romanucci and Della Salda, 2013). Rapid diagnosis, cooling and presentation to a veterinary hospital in under $1.5 \mathrm{hrs}$ have been shown to be critical factors in patient survival (Bruchim et al., 2006). This study has shown that healthy dogs completing short periods of routine exercise in the UK can reach a RT of $40^{\circ} \mathrm{C}$, highlighting the potential risks facing dogs exercising over longer periods during the warmer spring and summer months.

Gomart et al., (2014) suggested using correction factors to improve the reliability of the TMT when compared to RT, but did not report how significant these improvements were. This required using three different correction factors ranging from $+0.2^{\circ} \mathrm{C}$ to $+0.6^{\circ} \mathrm{C}$ determined by gender and coat type. In practice, this would be impractical to recommend to owners. These factors also assume that RT minus TMT is consistent for every dog, which is not supported by the findings of this study. The results of the present study would support using a correction factor of $0.4^{\circ} \mathrm{C}$ for all dogs, as this resulted in no significant difference between RT and TMT $+0.4^{\circ} \mathrm{C}$. This suggests that TMT $+0.4^{\circ} \mathrm{C}$ is a suitable alternative indicator of body temperature, when rectal thermometry is not practical.

As most studies comparing RT to TMT have found that TMT underreports body temperature, a simpler method of ensuring non-veterinary professionals (e.g. pet owners) are aware of this difference, would be to establish normal TMT reference ranges. The PetTemp instruction manual and company website currently reports a normal ear temperature range of 37.7 to $39.4^{\circ} \mathrm{C}$ (Admon, 2016). The findings of this study suggest that this "normal" range would result in hyperthermia going undetected $79 \%$ of the time, and suggest a normal resting TMT range of $36.7^{\circ} \mathrm{C}$ to $38.8^{\circ} \mathrm{C}$. Konietschke et al. (2014) used 62 dogs to establish a normal rectal temperature range, the reported range of aural temperatures in those animals was 37.1 to $39.1{ }^{\circ} \mathrm{C}$, however they did not use a 
veterinary specific aural thermometer and the measurements were obtained in a clinical setting. Additional research is required to establish a normal TMT reference range in dogs.

The main reasons pet owners measure their dog's temperature are to identify signs of ill health, or when exercising a dog at risk of developing exertional hyperthermia. In both situations identification of hyperthermia is the trigger for action by the owner. The dog owner either seeks veterinary attention for their animal in the case of illness, or stops exercising and begins cooling their animal in the event of exertional hyperthermia. In this study the TMT $+0.4^{\circ} \mathrm{C}$ correction factor improved identification of hyperthermia, but also then identified seven dogs as hyperthermic who were normothermic on RT. In a clinical setting this over reporting of body temperature could complicate patient care, however rectal thermometry is still gold standard for patient monitoring so it is unlikely this would actually harm any patients. In a non-clinical setting over reporting body temperature might result in owners seeking veterinary attention or stopping a dog's exercise needlessly, but neither of these situations would cause any harm to the dog. Conversely, if owners continue to rely on the current "normal" ear temperature range, they may be reassured that their dog's temperature is normal, when in fact it could be hyperthermic. If they failed to seek veterinary care or continued exercising their dog, this could have dangerous consequences. It could therefore be argued that under-reporting hyperthermia is more dangerous than over-reporting hyperthermia, especially for animals at risk of heatstroke where delaying seeking veterinary treatment increases the risk of mortality (Bruchim, 2006).

At present, the main temperature monitoring method available to owners is rectal thermometry, and as previously mentioned, RT is not tolerated in all dogs, and often requires additional restraint by an assistant (Lamb and McBrearty, 2013). RT monitoring may therefore not be possible for many dog owners wishing to monitor their pet's body temperature at home, or whilst exercising. The Vet-Temp and Pet-Temp auricular thermometers, offer a potential solution to that problem, and are tolerated well in most dogs $(211 / 212$ dogs), with only $24 \%$ requiring additional restraint in a veterinary setting (Lamb and McBrearty, 2013). For owners of athletic dogs completing strenuous exercise, or competing in hot climates, the aural thermometers offer a method of monitoring their dog for heatstroke, a potentially fatal condition. However, they should be advised to use a correction factor or specific ear temperature reference range to prevent under reporting of hyperthermia.

Whilst power analysis was used to determine the number of dogs recruited, the sample size was relatively small compared to some of the previous veterinary hospital based sample populations. As the study recruited a range of dog breeds, ages, sizes and coat types, the effects of these differences could not be evaluated due to the small number of dogs. Ideally, TMT would be compared to blood temperature in healthy dogs with exertional hyperthermia to fully evaluate this temperature recording method, however this would be both impractical and unethical.

Due to the variable types, intensities and duration of exercise undertaken, only 14 dogs reached a temperature considered to be hyperthermic. This limited the evaluation of the aural device for identifying hyperthermia. Recruiting a group of dogs all completing the same type and duration of intense exercise could potentially standardise the elevation in temperature, however individual variation would still impact the overall change in body temperature as reported by Angle and Gillette (2011). Such selective canine recruitment, would also potentially limit the application of any results generated, as intensive canine sporting activities often attract specific breeds or ages of dogs, meaning the younger, older or less sporting breeds would not be represented.

\section{Conclusion}


In line with previous research reported in a clinical setting, this study found that TMT measured consistently lower than RT. The hypothesis that dogs, like humans, would show greater differences in RT minus TMT following exercise, has not been supported by the findings of this study. This suggests that auricular devices could offer a less invasive, better tolerated method of monitoring body temperature in exercising animals, where RT is not possible. Using a correction factor of TMT $+0.4^{\circ} \mathrm{C}$ improves the identification of hyperthermia, and results in no significant difference in RT minus TMT. Perhaps the simplest way to prevent hyperthermia going undetected, would be to establish normal reference ranges for canine tympanic membrane temperature, and ensure this reference range is communicated to dog owners using aural thermometers. The results from this study would suggest a normal resting TMT range of $36.7^{\circ} \mathrm{C}$ to $38.8^{\circ} \mathrm{C}$, however more research is needed to validate this range.

\section{Conflicts of interest:}

The authors have no conflicting interests to declare.

\section{References}

Admon (Advanced Monitors Corporation, California USA), 2016. Your Pet's Temperature. Available at: http://www.admon.com/your-pets-temperature/

Craig Angle, T., and Gillette, R., 2011. Telemetric measurement of body core temperature in exercising unconditioned Labrador retrievers. Canadian Journal of Veterinary Research 75: 157-159. ISSN: 08309000

Bruchim, Y., 2012. Canine Heatstroke. Israel Journal of Veterinary Medicine 67: 92-95. Retrieved from http://www.isrvma.org/

Bruchim, Y., Klement, E., Saragusty, J., Finkeilstein, E., Kaas, P. and Aroch, I., 2006. Heat stroke in dogs: a retrospective study of 54 cases (1999-2004) and analysis of risk factors for death. Journal of Veterinary Internal Medicine 20: 38-46. DOI: 10.1111/j.1939-1676.2006.tb02821.x.

Canine Health Foundation, 2015. Why it is critical to know your dog's normal body temperature at rest, at play and at work: using our understanding of working dogs to support performance dog health. Available at: http://www.akcchf.org/canine-health/sporting-field-dogs/Hyperthermia-Dr-Vamvakias-transcriptFINAL.pdf.

Drobatz, K.J., 2009. Chapter 167: Heat Stroke. In Silverstein D.C., and Hopper, K. (Eds.), Small Animal Critical Care Medicine. Missouri: Saunders Elsevier, pp. 723-726.

Goddard, L. and Phillips, C., 2011. Observation and assessment of the patient. In, BSAVA Textbook of Veterinary Nursing, $5^{\text {th }}$ Edition. Eds B. Cooper, E. Mullineaux and L. Turner. Gloucester; BSAVA, pp. 376.

Gomart, S. B., Allerton, F. J. W. and Gommeren, K., 2014. Accuracy of different temperature reading techniques and associated stress response in hospitalised dogs. Journal of Veterinary Emergency and Critical Care 24: 279-285. DOI: http://dx.doi.org/10.1111/vec.12155.

Gonzalez, A. M., Mann, F. A., Preziosi, D. E., Meadows, R. L. and Wagnermann, C. C., 2002. Measurement of body temperature by use of auricular thermometers versus rectal thermometers in 
dogs with otitis externa. Journal of the American Veterinary Medical Association 221: 378-380. DOI: 10.2460/javma.2002.221.378.

Greer, R. J., Cohn, L. A., Dodam, J. R., Wagner-Mann, C. C. and Mann, F. A., 2007. Comparison of three methods of temperature measurement in hypothermic, euthermic, and hyperthermic dogs. Journal of the American Veterinary Medical Association 230: 1841-1848.

Greenes, D. S. and Fleisher, G. R., 2004. When body temperature changes, does rectal temperature lag? The Journal of Pediatrics 144: 824-826. DOI: 10.1016/j.jpeds.2004.02.037.

Hall, E.J. and Carter, A., 2016. Heatstroke - providing evidence-based advice to dog owners. Veterinary Nursing Journal 31: 359-363. DOI: 10.1080/17415349.2016.1245119.

Hartnack, S., 2014. Issues and pitfalls in method comparison studies. Veterinary Anaesthesia and Analgesia 41: 227-232. DOI: 10.1111/VAA.12143.

Huang, H. P and Shih, H. M., 1999. Use of infrared thermometry and effect of otitis externa on external ear canal temperature in dogs. Journal of the American Veterinary Medical Association 213: 76-79.

Huang, H. P. and Huang, H. M., 1999. Effects of ear type, sex, age, body weight, and climate on temperatures in the external acoustic meatus of dogs. American Veterinary Research Journal 60: 1173-1176.

Huggins, R., Glaviano, N., Meglish, N., Casa N. J. and Hertel, J., 2012. Comparison of rectal and aural core body temperature thermometry in hyperthermic, exercising individuals: a meta-analysis. Journal of Athletic Training 47: 329-338. DOI: 10.4085/1062-6050-47.3.09.

Jendritzy, G., De Dear, R. and Havenith, G., 2012. UTCI - Why another thermal index? International Journal of Biometeorology 56: 421-428. DOI 10.1007/s00484-011-0513-7.

Johnson, S.I., McMichael, M and White, G., 2006. Heatstroke in small animal medicine: a clinical practice review. Journal of Veterinary Emergency and Critical Care 16: 112-119.

DOI: http://dx.doi.org/10.1111/j.1476-4431.2006.00191.x.

Konietschke, U., Kruse, B. D., Muller, R., Stockhaus, C., Hartmann, K. and Wehner, A., 2014. Comparison of auricular and rectal temperature measurement in normothermic, hypothermic, and hyperthermic dogs. Tierärztliche Praxis Kleintiere 42: 13-19. ISSN: 1434-1239.

Lamb, V. and McBrearty, A. R., 2013. Comparison of rectal, tympanic membrane and axillary temperature measurement methods in dogs. Veterinary Record 173: 524-528. DOI:

$10.1136 / v r .101806$.

Levy, J.K., Nutt, K.R. and Tucker, S.J., 2015. Reference interval for rectal temperature in healthy confined adult cats. Journal of Feline Medicine and Surgery 17: 950-952. DOI: $10.1177 / 1098612 X 15582081$.

Miller, J. B., 2009. Hyperthermia and fever. In, Small Animal Critical Care Medicine. Eds D.C. Silverstein and Hopper, K. Missouri: Saunders-Elsevier. pp. 21-26.

Newsham, K. R., Saunders, J. E. and Nordin, E.S., 2002. Comparison of rectal and tympanic thermometry during exercise. Southern Medical Journal 9: 804-810. ISSN:1541-8243.

Niven, D. J., Gaudet, J. E., Laupland, K. B., Mrklas, K. J., Roberts, D. J. and Stelfox, H. T., 2015. Accuracy of peripheral thermometers for estimating temperature: a systematic review and metaanalysis. Annals of Internal Medicine 163: 768-777. DOI: 10.7326/M15-1150. 
Osinchuk, S., Taylor, S. M., Shmon, C. L., Pharr, J., and Campbell, J. 2014. Comparison between core temperatures measured telemetrically using the CorTemp ${ }^{\circledR}$ ingestible temperature sensor and rectal temperature in healthy Labrador retrievers. The Canadian Veterinary Journal 55: 939-945.

Piccione, G., Giannetto, C., Fazio, F. and Giudice, E., 2011. Accuracy of auricular temperature determination as body temperature index and its daily rhythmicity in healthy dog. Biological Rhythm Research 42: 437-443. DOI:http://dx.doi.org/10.1080/09291016.2010.526425.

Reniker, A and Mann, F.A., 2002. Understanding and treating heat stroke. Veterinary Medicine 97: 344-355. ProQuest document ID 195483945. Retrieved from http://search.proquest.com.

Rexroat, J., Benish, K. and Fraden, J., 1999. Clinical Accuracy of Vet-Temp ${ }^{\mathrm{TM}}$ Instant Ear Thermometer Comparative Study with Dogs and Cats (online). Advanced Monitors Corporation. Available at: http://www.admon.com/wp-content/uploads/2010/09/Humane-Society-White-Paper.pd. Accessed September 2015

Romanucci, M. and Della Salda, L., 2013. Pathophysiology and pathological findings of heatstroke in dogs. Veterinary Medicine: Research and Reports 4: 1-9. DOI https://doi.org/10.2147/VMRR.S29978.

Seymour, J., 2007. Observation and Assessment of the patient. In, BSAVA Textbook of Veterinary Nursing, 4th Edition. Eds D. Lane, B. Cooper and L. Turner. Gloucester; BSAVA, pp. 233.

Smith, V. A., Lamb, V. and McBrearty, A. R., 2015. Comparison of axillary, tympanic membrane and rectal temperature measurement in cats. Journal of Feline Medicine and Surgery 17: 1028-1034. DOI: $10.1177 / 1098612 X 14567550$.

Sousa, M. G., Carareto, R., Pereira-Junior, V. A. and Aquino, M. C. C., 2011. Comparison between auricular and standard rectal thermometers for the measurement of body temperature in dogs. The Canadian Veterinary Journal. La Revue Veterinaire Canadienne 52: 403-406. ISSN: 0008-5286.

Sousa, M. G., Carareto, R., Pereira-Junior, V. A. and Aquino, M. C. C., 2013. Agreement between auricular and rectal measurements of body temperature in healthy cats. Journal of Feline Medicine and Surgery 15: 275-279. DOI: http://dx.doi.org/10.1177/1098612X12464873.

Southward, E. S., Mann, F. A., Dodam, J. and Wagner-Mann, C. C., 2006. A comparison of auricular, rectal and pulmonary artery temperature in dogs with anaesthesia induced hypothermia. Journal of Veterinary Emergency and Critical Care 16: 172-175. DOI: http://dx.doi.org/10.1111/j.14764431.2005.00158.x.

The Kennel Club, 2016. Canicross. Available at: http://www.thekennelclub.org.uk/activities/canicross/

Wiedemann, G. G. S., Scalon, M. C., Paludo, G., Silva, I. O. and Boere, V., 2006. Comparison between tympanic and anal temperature with a clinical infrared ray thermometer in dogs. Arquivo Brasileiros Medicina Veterinaria Zootecnia 58: 503-505. DOI: 10.1590/S0102-09352006000400008.

Yanmaz, L. E., Dogan, E. and Okumus, Z., 2015. Comparison of rectal, eye and ear temperatures in Kangal breed dogs. Kafkas Univ Vet Fak Derg 21: 615-617. DOI: http://dx.doi.org/10.9775/kvfd.2015.13037) 